\title{
Bilangan Kromatik Lokasi $n$ Amalgamasi Bintang yang dihubungkan oleh suatu Lintasan
}

\author{
$\operatorname{Asmiati~}^{1}$ \\ ${ }^{1}$ Jurusan Matematika, Fakultas MIPA, Universitas Lampung \\ Jl. Brodjonegoro No. 1 Gd. Meneng, Bandar Lampung \\ ${ }^{1}$ asmiati308@yahoo.com, asmiati.1976@fmipa.unila.ac.id
}

\begin{abstract}
Abstrak
Bilangan kromatik lokasi graf diperkenalkan oleh Chartrand et al. pada tahun 2002. Konsep ini merupkan perpaduan dari konsep dimensi partisi dan pewarnaan graf. Penentuan bilangan kromatik lokasi suatu graf dilakukan dengan mengkonstruksi batas atasnya dan penentuan batas bawahnya. Dalam paper ini, kami mengkaji tentang bilangan kromatik lokasi amalgamasi bintang tertentu, yang dinotasikan dengan $n S_{k, m}$. Bilangan kromatik lokasi $n S_{k, m}$ untuk $k, m \geq 2, k \leq m$ dengan $n, k, m$ bilangan asli adalah $(m+1)$, jika $1 \leq n \leq\left\lfloor\frac{m}{k-1}\right\rfloor$ dan $(m+2)$ untuk $n \leq\left\lfloor\frac{m}{k-1}\right\rfloor$.

Kata kunci: amalgamasi bintang, bilangan kromatik lokasi graf, pewarnaan graf.
\end{abstract}

\begin{abstract}
The locating chromatic number of a graph was introduced by Chartrand et al in 2002. This concept is combined from the graph partition dimension and graph coloring. Determining the locating chromatic number of graph with construct the upper bound and the lower bound of the graph. In this paper, we determine the locating chromatic number for certain amalgamation of stars, denoted by $n S_{k, m}$. We prove that the locating chromatic number, $n S_{k, m}$ for $k, m \geq 2, k \leq m$ natural numbers $n, k, m$ is $(m+1)$, if $1 \leq n \leq\left\lfloor\frac{m}{k-1}\right\rfloor$ and $(m+2)$ for $n \leq\left\lfloor\frac{m}{k-1}\right\rfloor$.

Keywords : amalgamation of stars, locating-chromatic number of graph, graph coloring
\end{abstract}

\section{Pendahuluan}

Bilangan kromatik lokasi pada suatu graf merupakan pengembangan konsep dimensi partisi (Chartrand, et al.[6]) dan pewarnaan suatu graf. Berikut ini diberikan definisi bilangan kromatik lokasi graf yang diambil dari Chartrand, et al. [7]. Misalkan $c$ suatu pewarnaan titik pada graf $G$ dengan warna titik $u$ tidak sama dengan warna titik $v(c(u) \neq c(v))$ untuk $u$ dan $v$ yang bertetangga di $G$. Misalkan $C_{i}$ himpunan titik-titik yang diberi warna $i$, yang selanjutnya disebut kelas warna dan $\Pi=\left\{C_{1}, C_{2}, \ldots, C_{k}\right\}$ adalah himpunan yang terdiri dari kelas - kelas warna dari $V(G)$. Kode warna $c_{\Pi}(v)$ dari $v$ adalah k-pasang terurut $\left(d\left(v, C_{1}\right), d\left(v, C_{2}\right), \ldots, d\left(v, C_{k}\right)\right)$ dengan $d\left(v, C_{i}\right)=\min \left\{d(v, x) \mid x \in C_{i}\right\}$ untuk $1 \leq i \leq k$.

2000 Mathematics Subject Classification: 05C12, 05C15.

Received: 2017-04-18; accepted: 2017-11-01 
Selanjutnya, $k$-pasang terurut dari kode warna tersebut, kita nyatakan dengan komponen ke$1, \ldots$, komponen ke- $k$. Jika setiap titik di $V(G)$ mempunyai kode warna yang berbeda, maka $c$ disebut pewarnaan lokasi dari graf $G$. Banyaknya warna minimum yang digunakan untuk pewarnaan lokasi tersebut disebut bilangan kromatik lokasi dari $G$, dan dinotasikan dengan $\chi_{L}(G)$.

Teorema 1.1. (Chartrand, et al.[7]) Misalkan G graf terhubung dan c suatu pewarnaan lokasi pada $G$. Jika s dan $t$ adalah dua titik berbeda di $G$ sedemikian sehingga $d(s, u)=d(t, u)$ untuk setiap $u \in V(G) \backslash\{s, t\}$, maka $c(s) \neq c(t)$. Dalam hal khusus, jika $s$ dan $t$ adalah titik-titik yang tidak bertetangga di $G$ sedemikian sehingga $N(s)=N(t)$, maka $c(s) \neq c(t)$.

Bukti. Misalkan $c$ adalah suatu pewarnaan lokasi pada graf terhubung $G$ dan misalkan $\Pi=\left\{C_{1}, C_{2}, \ldots, C_{k}\right\}$ adalah himpunan kelas-kelas warna dari $V(G)$. Untuk titik $s, t \in V(G)$, andaikan $c(s)=c(t)$ sedemikian sehingga $s$ dan $t$ berada dalam kelas warna yang sama, misal $C_{i}$ dari $\Pi$. Akibatnya, $d\left(s, C_{i}\right)=d\left(t, C_{i}\right)=0$. Karena $d(s, u)=d(t, u)$ untuk setiap $u \in V(G) \backslash\{s, t\}$ maka $d\left(s, C_{i}\right)=d\left(t, C_{j}\right)$ untuk setiap $j \notin i, 1 \leq j \leq k$. Akibatnya, $c_{\Pi}(s)=c_{\Pi}(t)$ sehingga $c$ bukan pewarnaan lokasi. Jadi $c(s) \neq c(t)$.

Akibat 1.2. (Chartrand, et al.[7]) Jika $G$ adalah suatu graf terhubung dan terdapat titik yang bertetangga dengan $k$ daun di $G$, maka $\chi_{L}(G) \geq k+1$.

Kajian bilangan kromatik lokasi pada suatu graf merupakan hal yang menarik hingga saat ini, karena belum adanya teorema yang dapat digunakan untuk menentukan bilangan kromatik lokasi graf secara umum. Pada graf pohon, Chartrand et al. [7] telah mendapatkan bilangan kromatik lokasi pada graf lintasan, graf bintang, graf bintang ganda, graf ulat, dan graf pohon berorde $n \geq 5$, yang memiliki bilangan kromatik lokasi $3,4, \ldots, n$ kecuali $n-1$. Selanjutnya Asmiati et al. [1],[2] telah mendapatkan bilangan kromatik lokasi pada graf amalgamasi bintang homogen dan graf kembang api; Des Welyyanti [8] untuk graf pohon n-ary lengkap, dan Asmiati [4] pada graf amalgamasi bintang tak homogen.

Beberapa kajian tentang karakterisasi graf amalgamasi pohon dengan bilangan kromatik lokasi tertentu juga telah dilakukan diantaranya adalah: Chartrand et al. [7] telah mendapatkan karakterisasi graf berbilangan kromatik lokasi $(n-1)$ atau $(n-2)$; Asmiati et al. [3] untuk karakterisasi graf memuat siklus berbilangan kromatik lokasi tiga; Baskoro et al. [5] telah mendapatkan karakterisasi semua pohon berbilangan kromatik lokasi tiga.

Berdasarkan hasil-hasil yang sudah didapatkan oleh Asmiati et al [1] dan Asmiati [4], maka pada paper ini didiskusikan tentang bilangan kromatik lokasi amalgamasi bintang tertentu, yaitu n buah amalgamasi bintang homogen yang dihubungkan oleh sebuah lintasan.

\section{Hasil dan Pembahasan}

Misalkan $S_{m+2}$, adalah graf bintang dengan $(m+2)$ titik. Amalgamasi bintang, $S_{k, m}$ dengan $k, m \geq 2$ adalah graf yang diperoleh dari $(k-1)$ buah graf bintang $S_{m+2}$, dengan cara menyatukan sebuah daun dari setiap graf $S_{m+2}$. Titik penyatuan tersebut disebut titik pusat $S_{k, m}$. Graf $n S_{k, m}$ adalah graf yang diperoleh dari $n$ kopi graf $S_{k, m}$, yang mana setiap titik pusat $S_{k, m}$, yaitu $x_{i}, i=1,2, \ldots, n$ dihubungkan oleh suatu lintasan dan $(n-1)$ titik baru, dinotasikan $y_{i}, i=1,2, \ldots, n-1$ merupakan titik-titik subdivisi pada sisi $x_{i} x_{i+1}, i=$ $1,2, \ldots, n-1$. Selanjutnya, pada graf $n S_{k, m}$, titik pusat untuk setiap $S_{m+2}$, dinotasikan dengan $l_{j}^{i}, i=1,2,3, \ldots, n$ dan $j=1,2,3, \ldots, k-1$, sedangkan daun ke- t yang menempel pada titik $l_{j}^{i}$, dinotasikan dengan $l_{j t}^{i}, t=1,2,3, \ldots, m$.

Pada bagian ini akan didiskusikan bilangan kromatik lokasi $n S_{k, m}$ untuk $k \leq m$ dengan $n, k, m$ bilangan asli. 
Teorema 2.1. Misalkan $n S_{k, m}$ adalah graf amalgamasi bintang tertentu untuk $k, m \geq 2$, $k \leq m$, dengan $n, k, m$ bilangan asli

$$
\chi_{L}\left(n S_{k, m}\right)=\left\{\begin{array}{l}
m+1 ; 1 \leq n \leq\left\lfloor\frac{m}{k-1}\right\rfloor \\
m+2 ; \text { lainnya }
\end{array}\right.
$$

Bukti. Pertama-tama akan ditentukan batas bawah dan batas atas dari $\chi_{L}\left(n S_{k, m}\right)$ untuk $1 \leq n \leq\left\lfloor\frac{m}{k-1}\right\rfloor$. Karena setiap titik $l_{j}^{i}$ untuk $i=1,2,3, \ldots, n$ dan $j=1,2,3, \ldots, k-1$ bertetangga dengan $m$ daun, maka berdasarkan Akibat $1.2, \chi_{L}\left(n S_{k, m}\right) \geq m+1$. Selanjutnya akan ditentukan batas atas dari $\chi_{L}\left(n S_{k, m}\right)$ untuk $1 \leq n \leq\left\lfloor\frac{m}{k-1}\right\rfloor$. Misalkan $c$ adalah suatu pewarnaan dari $V\left(n S_{k, m}\right)$ menggunakan $(m+1)$ warna, yaitu

- $c\left(x_{i}\right)=1$, untuk $i=1,2,3, \ldots, n$;

- $c\left(y_{i}\right)=2$, untuk $i$ ganjil dan $c\left(y_{i}\right)=3$ untuk $i$ genap, $i=1,2,3, \ldots, n-1$;

- Warna untuk $l_{j}^{i}$ adalah berurutan dari $2,3, \ldots,(m+1)$ untuk $i=1,2,3, \ldots, n$ dan $j=1,2,3, \ldots, k-1$;

- $\left\{c\left(l_{j t}^{i}\right)\right\}=\{1,2,3, \ldots, m+1\} \backslash\left\{c\left(l_{j}^{i}\right)\right\}$ untuk $i=1,2,3, \ldots, n$ dan $j=1,2,3, \ldots, k-1$ dan $t=1,2,3, \ldots, m$.

Akibatnya pewarnaan $c$ akan membangun suatu partisi $\Pi=\left\{C_{1}, C_{2}, C_{3}, \ldots, C_{m+1}\right\}$ pada $V\left(n S_{k, m}\right)$, dengan $C_{i}$ adalah himpunan dari semua titik yang berwarna $i$ untuk $i=$ $1,2,3, \ldots, m+1$.

Selanjutnya akan ditunjukkan bahwa kode warna untuk setiap titik di $V\left(n S_{k, m}\right)$ berbeda. Misalkan $u, v \in V\left(n S_{k, m}\right)$ dan $c(u)=c(v)$ maka pandang kasus-kasus berikut ini:

- Jika $u=x_{i}, v=x_{k}$ untuk suatu $i, k$ dan $i \neq k$, maka $c_{\Pi}(u) \neq c_{\Pi}(v)$ karena titik $u$ dan $v$, masing-masing mempunyai tetangga dengan himpunan warna berbeda.

- Jika $u=x_{i}, v=l_{j t}^{i}$ untuk suatu $i, j, t$, maka $c_{\Pi}(u) \neq c_{\Pi}(v)$, karena pada $c_{\Pi}(u)$ terdapat sekurang-kurangnya dua komponen bernilai satu, sedangkan pada $c_{\Pi}(v)$ memuat tepat satu komponen yang bernilai 1.

- Jika $u=y_{i}, v=l_{j}^{i}$ untuk suatu $i, j$, maka $c_{\Pi}(u) \neq c_{\Pi}(v)$, karena titik $u$ bertetangga dengan titik yang berwarna $(m+1)$, sedangkan titik $v$ tidak.

- Jika $u=y_{i}, v=l_{j t}^{i}$ untuk suatu $i, j, t$, maka $c_{\Pi}(u) \neq c_{\Pi}(v)$, karena pada $c_{\Pi}(u)$ terdapat tepat dua komponen yang bernilai 1 , sedangkan pada $c_{\Pi}(v)$ terdapat tepat satu komponen yang bernilai satu.

- Jika $u=l_{j}^{i}, v=l_{j t}^{i}$ untuk suatu $i, j, t$, maka $c_{\Pi}(u) \neq c_{\Pi}(v)$, karena pada $c_{\Pi}(u)$ terdapat sekurang-kurangnya dua komponen bernilai satu, sedangkan pada $c_{\Pi}(v)$ terdapat tepat satu komponen yang bernilai satu.

- Jika $u=l_{j t}^{i}, v=l_{h t}^{i}$ untuk suatu $i, j, h, t$ maka $c_{\Pi}(u) \neq c_{\Pi}(v)$ karena $c\left(l_{j}^{i}\right) \neq c\left(l_{h}^{i}\right)$.

Dapat dilihat bahwa kode warna semua titik di $V\left(n S_{k, m}\right)$ untuk $n \leq\left\lfloor\frac{m}{k-1}\right\rfloor$ adalah berbeda, maka $c$ merupakan pewarnaan lokasi. Jadi $\chi_{L}\left(n S_{k, m}\right) \leq m+1$. Akibatnya diperoleh $\chi_{L}\left(n S_{k, m}\right)=m+1$.

Selanjutnya akan ditentukan batas bawah dan batas atas untuk $n>\left\lfloor\frac{m}{k-1}\right\rfloor$. Berdasarkan Akibat 1.2, diperoleh $\chi_{L}\left(n S_{k, m}\right) \geq m+1$ untuk $n>\left\lfloor\frac{m}{k-1}\right\rfloor$. Akan ditunjukkan bahwa $(m+1)$ tidaklah cukup untuk mewarnai $n S_{k, m}$. Untuk suatu kontradiksi, andaikan terdapat pewarnaan lokasi $c$ pada $n S_{k, m}$ menggunakan $(m+1)$ warna. Karena $n>\left\lfloor\frac{m}{k-1}\right\rfloor$, maka terdapat suatu $i, j, k$ dengan $i \neq k$ sedemikian hingga $c\left(l_{j}^{i}\right)=c\left(l_{j}^{k}\right)$ dan $\left\{c\left(l_{j t}^{i}\right)\right\}=\left\{c\left(l_{j t}^{k}\right)\right\}$. Akibatnya $c_{\Pi}\left(l_{j}^{i}\right)=c_{\Pi}\left(l_{j}^{k}\right)$, maka $c$ bukan merupakan pewarnaan lokasi, suatu kontradiksi. Jadi $\chi_{L}\left(S_{k, m}\right) \geq m+2$ untuk $n>\left\lfloor\frac{m}{k-1}\right\rfloor$. 
Misalkan $c$ adalah pewarnaan $n S_{k, m}$ menggunakan $(m+2)$ warna untuk $n>\left\lfloor\frac{m}{k-1}\right\rfloor$. Beri warna titik titik di $n S_{k, m}$ sebagai berikut:

- $c\left(x_{i}\right)=1$, untuk $i=1,2,3, \ldots, n$;

- $c\left(y_{i}\right)=2$, untuk $i$ ganjil dan $c\left(y_{i}\right)=3$ untuk $i$ genap, $i=1,2,3, \ldots, n$;

- Warna untuk $l_{j}^{i}$, dengan $j=1,2,3, \ldots, k-1$ adalah berurutan dari $2,3, \ldots, k$ untuk $i$ ganjil dan berurutan dari $(k+1), \ldots,(m+1)$ untuk $i$ genap;

- Jika $A=1,2,3, \ldots, m+2$, didefinisikan

$$
\left\{c\left(l_{j t}^{i}\right) \mid t=1,2,3, \ldots, m\right\}=\left\{\begin{array}{l}
A \backslash\{1,2\}, \text { jika } i=1, j=1 ; \\
A \backslash\{m+2\}, \text { lainnya. }
\end{array}\right.
$$

Pewarnaan $c$ akan membangun suatu partisi $\Pi$ pada $V\left(n S_{k, m}\right)$. Akan ditunjukkan bahwa kode warna semua titik di $n S_{k, m}$ berbeda.

$$
c_{\Pi}\left(x_{1}\right)=\left\{\begin{array}{l}
0, \text { komponen ke }-1 ; \\
1, \text { komponen ke- } 2 ; \\
2, \text { komponen ke }-(m+1) ; \\
2, \text { lainnya. }
\end{array}\right.
$$

Untuk $i \geq 3$ ganjil

$$
c_{\Pi}\left(x_{i}\right)=\left\{\begin{array}{l}
0, \text { komponen ke }-1 \\
1, \text { komponen ke }-2 \text { dan ke }-k \\
2, \text { komponen ke }-(m+1) \\
i+3, \text { lainnya }
\end{array}\right.
$$

Untuk $i \geq 2$ genap

$$
\begin{aligned}
& c_{\Pi}\left(x_{i}\right)=\left\{\begin{array}{l}
0, \text { komponen ke }-1 ; \\
2, \text { komponen ke- } 2 ; \\
1, \text { komponen ke }-(m+1) \\
i+3, \text { lainnya. }
\end{array}\right. \\
& c_{\Pi}\left(y_{1}\right)=\left\{\begin{array}{l}
1, \text { komponen ke }-1 ; \\
0, \text { komponen ke }-2 ; \\
1, \text { komponen ke }-k ; \\
3, \text { komponen ke }-(m+1) ; \\
3, \text { lainnya. }
\end{array}\right.
\end{aligned}
$$

Untuk $i \geq 2$ ganjil

$$
c_{\Pi}\left(y_{i}\right)=\left\{\begin{array}{l}
1, \text { komponen ke }-1 \\
0, \text { komponen ke }-2 ; \\
1, \text { komponen ke }-3 \\
3, \text { komponen ke }-(m+1) ; \\
i+2, \text { lainnya } .
\end{array}\right.
$$

Untuk $i \geq 2$ genap

$$
c_{\Pi}\left(y_{i}\right)=\left\{\begin{array}{l}
1, \text { komponen ke }-1 \\
1, \text { komponen ke }-2 \\
0, \text { komponen ke }-3 \\
3, \text { komponen ke }-(m+1) ; \\
i+2, \text { lainnya } .
\end{array}\right.
$$




$$
\begin{aligned}
& c_{\Pi}\left(l_{1}^{1}\right)=\left\{\begin{array}{l}
1, \text { komponen ke }-1 ; \\
1, \text { komponen ke }-(m+1) ; \\
1, \text { lainnya } .
\end{array}\right. \\
& c_{\Pi}\left(l_{k-1}^{1}\right)=\left\{\begin{array}{l}
1, \text { komponen ke }-1 ; \\
0, \text { komponen ke }-(k-1) ; \\
1, \text { komponen ke }-(m+1) ; \\
3, \text { lainnya }
\end{array}\right.
\end{aligned}
$$

Untuk $j=2,3, \ldots, k-1$

$$
c_{\Pi}\left(l_{j}^{1}\right)=\left\{\begin{array}{l}
1, \text { komponen ke }-1 \\
0, \text { komponen ke }-(j+1) ; \\
1, \text { komponen ke }-(m+1) \\
3, \text { lainnya }
\end{array}\right.
$$

Untuk $i \geq 2, j=1,2,3, \ldots, k-1$

$$
\begin{gathered}
c_{\Pi}\left(l_{j}^{i}\right)=\left\{\begin{array}{l}
1, \text { komponen ke }-1 ; \\
1, \text { komponen ke }-2 ; \\
1, \text { komponen ke }-(m+1) ; \\
i+4, \text { lainnya }
\end{array}\right. \\
c_{\Pi}\left(l_{11}^{1}\right)=\left\{\begin{array}{l}
2, \text { komponen ke }-1 ; \\
1, \text { komponen ke }-2 ; \\
2, \text { komponen ke }-(m+1) ; \\
0, \text { lainnya }
\end{array}\right.
\end{gathered}
$$

Untuk $t=2,3, \ldots, m$

$$
\begin{gathered}
c_{\Pi}\left(l_{1 t}^{1}\right)=\left\{\begin{array}{l}
2, \text { komponen ke }-1 ; \\
1, \text { komponen ke }-2 ; \\
0, \text { komponen ke }-(t+1) ; \\
2, \text { komponen ke }-(m+1) ; \\
2, \text { lainnya. }
\end{array}\right. \\
c_{\Pi(}\left(l_{1 m}^{1}\right)=\left\{\begin{array}{l}
2, \text { komponen ke }-1 ; \\
1, \text { komponen ke }-2 ; \\
0, \text { komponen ke }-(m+1) ; \\
2, \text { lainnya } .
\end{array}\right. \\
c_{\Pi}\left(l_{(k-1) m}^{1}\right)=\left\{\begin{array}{l}
2, \text { komponen ke }-1 ; \\
1, \text { komponen ke }-(k-1) ; \\
0, \text { komponen ke }-(m+1) ; \\
4, \text { lainnya } .
\end{array}\right.
\end{gathered}
$$

Untuk $i \geq 2, j=1,2,3, \ldots, k-1, t=1,2,3, \ldots, m$

$$
c_{\Pi}\left(l_{j m}^{i}\right)=\left\{\begin{array}{l}
0, \text { komponen } k e-t \\
1, \text { komponen ke }-(j+1) \\
i+5, \text { lainnya } .
\end{array}\right.
$$


Karena hanya terdapat satu daun yang berwarna $(m+2)$, mengakibatkan kode warna semua titik di $V\left(n S_{k, m}\right)$ berbeda, maka $c$ merupakan pewarnaan lokasi pada $n S_{k, m}$. Jadi $\chi_{L}\left(n S_{k, m}\right) \leq m+2$ untuk $n>\left\lfloor\frac{m}{k-1}\right\rfloor$. Terbukti bahwa $\chi_{L}\left(n S_{k, m}\right)=m+2$.

Sebagai ilustrasi, diberikan pewarnaan lokasi $n S_{3,4}$ untuk $1 \leq n \leq 2$ yang dapat dilihat pada gambar berikut:

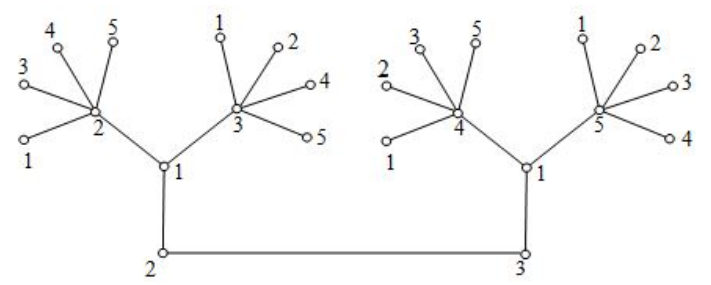

Gambar 1. Pewarnaan lokasi minimum pada graf $2 S_{3,4}$

Sebagai ilustrasi, diberikan pewarnaan lokasi $n S_{3,4}$ untuk $n>2$ yang dapat dilihat pada gambar berikut:

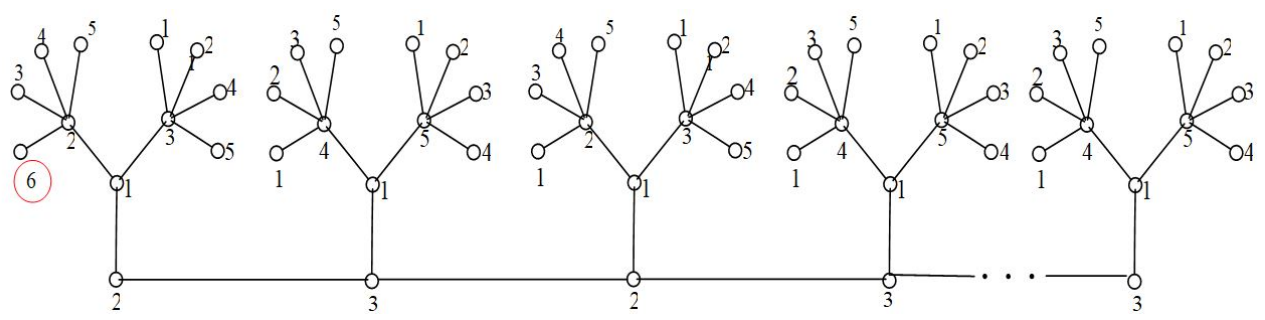

Gambar 2. Pewarnaan lokasi minimum pada graf $n S_{3,4}$ untuk $n>2$

\section{SimpUlan}

Bilangan kromatik lokasi pada graf $n S_{k, m}$ untuk $k, m \geq 2, k \leq m$, dengan $n, k, m$ bilangan asli adalah $(m+1)$, jika $1 \leq n \leq\left\lfloor\frac{m}{k-1}\right\rfloor$ dan $(m+2)$ untuk $n>\left\lfloor\frac{m}{k-1}\right\rfloor$. Penelitian ini dapat dilanjutkan untuk $k>m$.

\section{DAFtar Pustaka}

[1] Asmiati, H. Assiyatun, E.T. Baskoro, 2011, Locating- chromatic number of amalgamation of stars, ITB J.Sci., 43A, 1-8.

[2] Asmiati, H. Assiyatun, E.T. Baskoro, D. Suprijanto, R. Simanjuntak, S. Uttunggadewa, 2012, Locatingchromatic number of firecracker graphs, Far East J. Math.Sci., 63(1), 11-23.

[3] Asmiati, E.T. Baskoro, 2012, Characterizing of graphs containing cycle with locating-chromatic number three, AIP Conf. Proc., 1450, 351-357.

[4] Asmiati, Locating-chromatic number of non homogeneous amalgamation of stars, 2014, Far East J. Math. Sci., 93(1), 89-96.

[5] E. T. Baskoro, Asmiati, 2013, Characterizing all trees with locating-chromatic number 3, Elec. J. Graph Theory Appl. 1(2), 109-117. 
[6] G. Chartrand, E. Salehi, dan P. Zhang, 1998, On the partition dimension of graph, Congr. Numer., 130, $157-168$.

[7] G. Chartrand, D. Erwin, M.A. Henning, P.J. Slater, dan P. Zhang, 2003, Graph of order n with locatingchromatic number n-1, Discrete Math., 269, 65-79.

[8] Des Welyyanti, E.T. Baskoro, R. Simanjuntak, S. Uttunggadewa, 2013, On locating-chromatic number of complete n-ary tree, ACKE Int. J. Graphs Comb., 10(3), 309-319. 
122 Asmiati, JMI Vol 13 No 2 Oktober 2017, 115-121,doi:10.24198/jmi.v13.n2.11891.115-121 